\title{
Pregnant and alone in Uganda
}

Published at www.cmaj.ca on Sept. 1

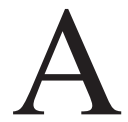
nnette Nakawuki, 15 years old and five months pregnant, waits outside a screening room at the Naguru Teenage Centre in Kampala, Uganda. She is here for a free antenatal check. The five girls surrounding her, all visibly pregnant, are here for the same reason.

At age 12, Nakawuki, an orphan, left her village to work in Kampala as a maid. The pay was terrible, so she entered a relationship with a man who could support her. When she became pregnant, the man left. "I came to the city for a better life," she says, "but this is what I am - pregnant and alone."

In addition to antenatal care, the centre, which receives about a dozen new pregnant teenagers a day, offers learning materials on reproductive health and safe sex. But according to Omega Aliru, a counsellor at the centre, education is often not enough for girls like Nakawuki. "Many girls come from poor families. As a result, they cannot easily negotiate sex with the older men who give them monetary support for sex, even if they knew about condoms and pills."

Many unintended pregnancies in Uganda are also unwanted. According to a 2005 study, an estimated 775000 women have unintended pregnancies each year, and about 297000 abortions are performed (Int Fam Plan Perspect 2005;31:183-91). Unless a pregnant woman's life is in danger, abortion is illegal in Uganda, so the procedure is often performed in unsafe conditions by people without medical training.

As a result, nearly 85000 women are treated annually for complications of abortion. Many of them die, which is one reason Uganda's maternal mortality rate is so high — about 435 women die per 100000 live births.

Decreasing this rate in Uganda and other African countries, and improving

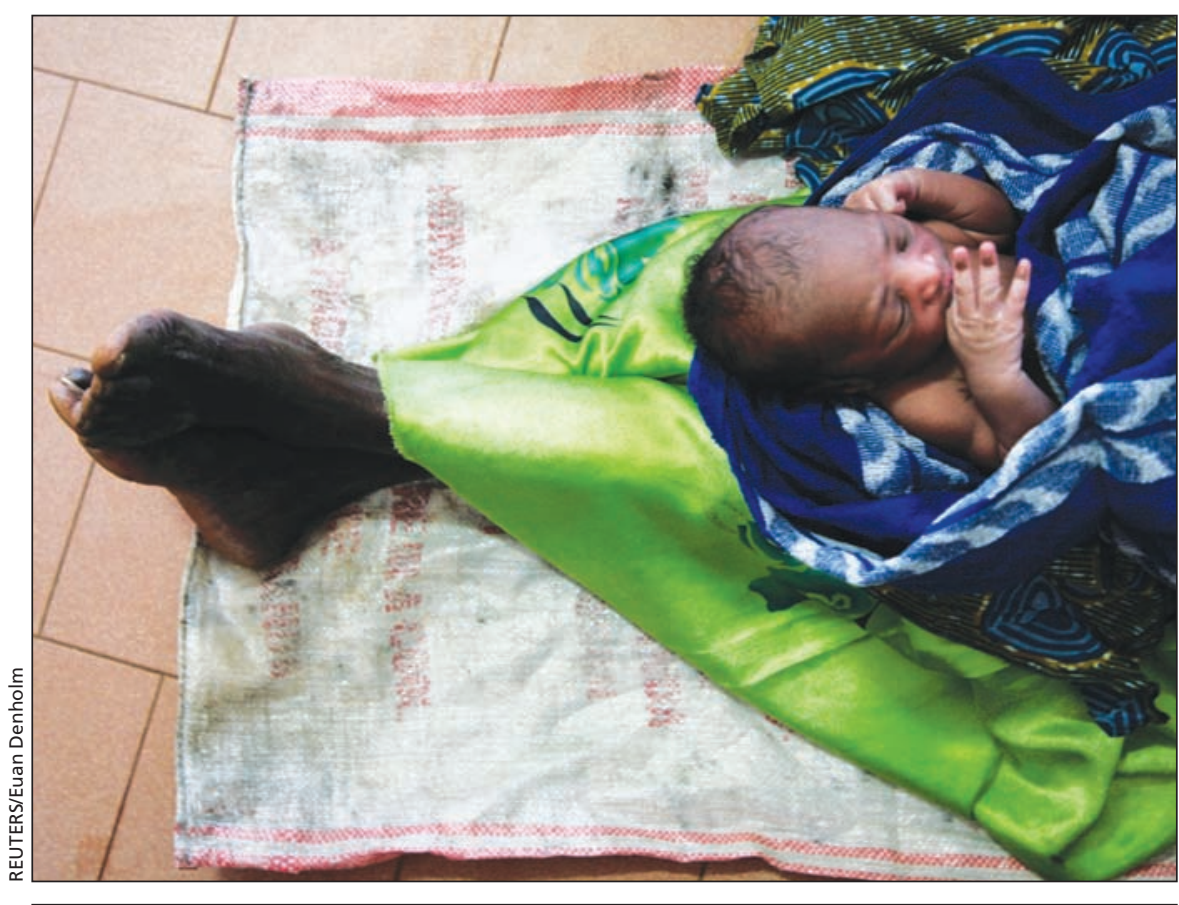

A woman holds holds her newborn grandson as she sits on the floor of Lacor hospital's maternity ward in northern Uganda.

maternal health in general, was a primary focus of a recent meeting of African nations in Kampala. The theme of the 15th Ordinary Session of the Summit of the African Union, held on July 19-27, was "Maternal, Infant and Child Health and Development in Africa."

At the event, however, Ugandan President Yoweri Museveni announced that Uganda would not meet Millennium Development Goal 5: reducing its maternal mortality ratio by three quarters by 2015. This failure, which Museveni blamed on corrupt health care workers and insufficient funding, is likely to be repeated in other countries in sub-Saharan Africa.

According to Joshua Kyallo, Uganda's country director for the African Medical and Research Foundation, such failures are unacceptable. "Africa shoulders the world's biggest burden of pregnancy-related deaths," he says. "One in 16 young women and teenage girls in sub-Saharan Africa is at risk of death due to pregnancy compli- cations. There has been progress but it's simply not good enough.'

At the summit in Kampala, activists called on leaders to abide by the 2001 Abuja Declaration to assign $15 \%$ of national budgets to health. Only Botswana, Rwanda, Niger, Malawi, Zambia and Burkina Faso have met this target. In June, however, Uganda did announce that 260 billion shillings (\$122 million) would be set aside for spending on maternal and reproductive health over the next five years.

This increase in funding will enable more young women in Uganda to access family planning services. This is one key to reducing unwanted pregnancies and unsafe abortions, says Fred Ntoni Nuwaha, a professor at the Makerere University Institute of Public Health in Kampala. "There is a high unmet need for family planning of $41 \%$, which leads to a high fertility rate and abortions," he says. "Availing family planning services to all women who require them has to be made a priority." 
Another priority in reducing Uganda's maternal mortality rate, says Nuwaha, is ensuring more African girls stay in school. "Women's education, if implemented effectively, it could reduce these deaths significantly," he says. "We should ensure that the girl child starts school and stays in school for at least 12 years."

Getting more women to give birth in hospitals would also improve maternal health, says Nuwaha. Most Ugandan women, about $62 \%$, deliver either by themselves or with unskilled workers outside health facilities. According to Nuwaha, this is because when health facilities are built, they often lack the capacity to make them functional in terms of human resources, medical equipment and operational budgets.

Getting more young women and girls to give birth instead of opting for unsafe abortions is another way to reduce Uganda's maternal mortality ratio. But, as Aliru knows all too well, this is a difficult task.

"We counsel them to keep the pregnancy, but few stay," she says. "Many go for unsafe abortions. I have met some of these girls afterwards ... at the post-abortion care clinic. Some of them die, and those who are lucky survive with abortion complications." Rosebell Kagumire, Kampala, Uganda

DOI:10.1503/cmaj.109-3330 